\title{
1
}

\section{High-Resolution Analysis of Genomic Copy Number Changes}

\author{
Mario Hermsen ${ }^{1}$, Jordy Coffa ${ }^{2}$, Bauke Ylstra ${ }^{3}$, Gerrit Meijer ${ }^{2}$, Hans Morreau ${ }^{4}$, \\ Ronald van Eijk ${ }^{4}$, Jan Oosting ${ }^{4}$ and Tom van Wezel ${ }^{4}$ \\ ${ }^{1}$ Department Otorrinolaringología, Instituto Universitario de Oncología del Principado de Asturias, \\ Oviedo, Spain \\ ${ }^{2}$ Department of Pathology, VU University Medical Center, Amsterdam, The Netherlands \\ ${ }^{3}$ Microarray Facility, VU University Medical Center, Amsterdam, The Netherlands \\ ${ }^{4}$ Department of Pathology, Leiden University Medical Center, Leiden, The Netherlands
}

\subsection{Introduction}

The analysis of DNA copy number changes throughout the whole genome started with the introduction of comparative genomic hybridization (CGH), first described in 1992 by Kallioniemi et al. [1]. This elegant technique was based on the competitive hybridization of two pools of fluorescent-labeled probes, one made up of whole-genome DNA of a test and another of a control sample, to a metaphase preparation of normal chromosomes. Along each chromosome, the fluorescent intensity of the test DNA was quantified and compared with the control intensity, resulting in 'relative copy number karyotypes.'

It appeared to be very difficult to reproduce the method in laboratories not specialized in chromosome techniques. Only after the publication of an article reviewing all steps in great detail did CGH become more widely applied [2], especially in cancer genetics. The possibility of using DNA obtained from formalin-fixed and paraffin-embedded (FFPE) samples opened up the way for retrospective studies of tumors with clinical follow-up data, enabling the identification of genetic changes related to tumor progression, invasion and metastasis [3].

Genomics: Essential Methods Edited by Mike Starkey and Ramnath Elaswarapu 
The resolution of what is now called classical CGH is limited to a chromosomal band, approximately $5-10 \mathrm{Mb}$. This was overcome by the introduction of array comparative genomic hybridization (aCGH) in 1997 [4, 5]. The method is essentially the same, but now an array of genomic DNA clones or oligonucleotides serves as hybridization target, rather than metaphase chromosomes. The resolution of aCGH is now defined by the choice and/or the number of DNA clones and later oligonucleotides, and another advantage is that it does not require karyotyping. At the present moment, aCGH using oligonucleotide or single nucleotide polymorphism (SNP) arrays is most widely applied [6].

Multiple ligation-dependent probe amplification (MLPA), developed and first published in 2002 by Schouten et al. [7], is an alternative DNA copy number analysis technique, especially when specific genes or chromosomal regions are already known to be of interest. MLPA requires only $20 \mathrm{ng}$ of DNA, enough to allow the simultaneous quantification of up to 50 different targets, which may be as small as 50 nucleotides. Another advantage of MLPA lies in its reproducibility and specificity, allowing application in a routine diagnostic setting while remaining time- and cost-efficient.

One increasingly important application is genomic profiling of FFPE samples. Across the world, large collections of FFPE samples with clinical follow-up exist. However, the DNA from FFPE samples shows varying levels of degradation depending largely on the length and the method of fixation, and on age of the specimen. This chapter aims to describe in detail the methods of oligonucleotide aCGH, SNP aCGH and MLPA, with special attention for the use of DNA obtained from FFPE samples. These techniques have primarily been used in cancer research; however, they are also suitable for the analysis of DNA copy number aberrations in human genetic disorders.

\subsection{Methods and approaches}

\subsubsection{Oligonucleotide aCGH}

The first whole-genome microarray contained 2400 large-insert genomic clones, primarily bacterial artificial chromosomes (BACs) [8]. With the total human genome covering about $3000 \mathrm{Mb}$ the resolution of this array is on average close to $1 \mathrm{Mb}$, which is about one order of magnitude higher than that obtained with classical CGH [1]. For a full coverage resolution, about 30000 BACs have been arrayed [9], increasing the resolution by another order of magnitude. However, producing such large numbers of BACs for aCGH is expensive and time consuming; and due to the large size of the BACs, the resolution limits for BAC aCGH resolution were reached.

Several laboratories used cDNA arrays, initially designed for expression profiling, as an alternative for measuring chromosomal copy number changes [10]. Even though this approach has certainly yielded valuable information, it cannot compete with the oligonucleotide platforms in terms of its maximal achievable resolution. Oligonucleotides allow a sheer infinite resolution, great flexibility and are cost effective [6]. They also enable the generation of microarrays for any organism for which the genome has been sequenced. Using the same oligonucleotide array for $\mathrm{CGH}$ and expression profiling allows direct comparison of mRNA expression and DNA copy number ratios. In addition, oligonucleotide arrays are being used, designed and accepted for expression profiling, and thus are widely available. 

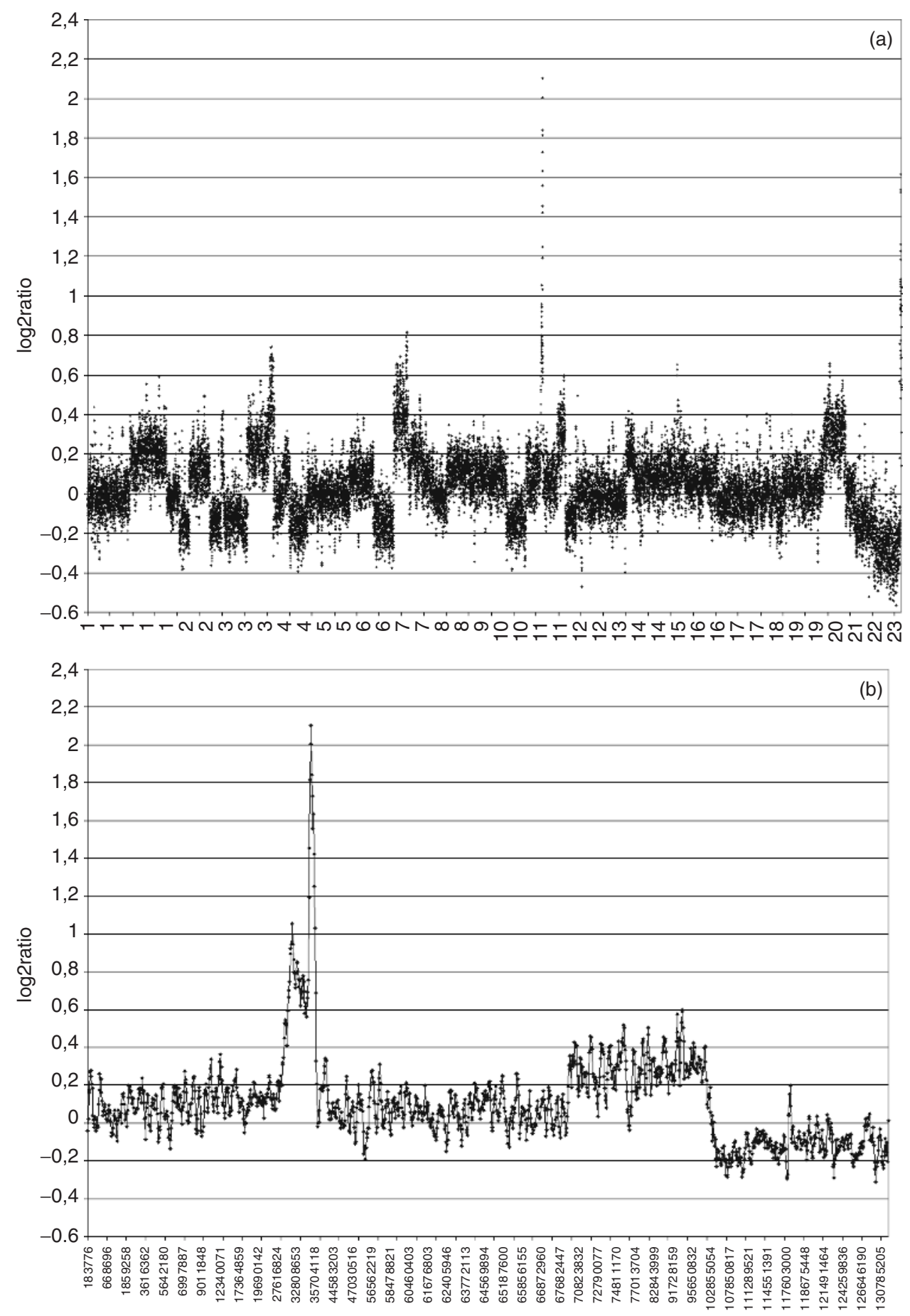

Figure 1.1 Example of oligonucleotide aCGH on tumor DNA extracted from FFPE. (a) All oligonucleotides ordered according to their chromosomal localization. (b) Oligonucleotides from chromosome 11 only. A marked amplification (indicated by an arrow) can be observed. 
Commercial oligonucleotide aCGH platforms include Illumina (60 mer), Operon (70 mer), Affymetrix (25 mer), Agilent (60 mer) and NimbleGen (45-85 bp), the latter with now up to 2.1 million oligonucleotides on the array [11]. The quality of the oligonucleotide aCGH platforms is rapidly improving, with single oligonucleotides rapidly reaching the sensitivity of single BAC clones. Not all of the current oligonucleotide aCGH platforms can make a definite call for loss or gain using a single oligonucleotide, but in some cases three to five adjacent oligonucleotides are necessary for a reliable call $[6,11]$. Moreover, owing to improvements in protocols, DNA isolated from FFPE tumor samples now works comparable to DNA from fresh material (Protocols 1.1-1.4) on long (>50 bp) oligonucleotide arrays (see Figure 1.1).

The principle of oligonucleotide aCGH is the same as all aCGH variants: Labeled tumor DNA (Protocol 1.5) competes with differentially labeled normal DNA for hybridizing to an array of oligonucleotides (Protocol 1.6). Using a specialized scanner and digital image processing software, the ratio of the two is measured per spot on the array. Deviations from the normal ratio of 1.0 , or the $\log _{2}$ ratio of 0.0 , represent a copy number aberration of genetic material in the tumor. The final result is DNA copy number information for all the oligonucleotides on the array, which can be ordered according to the chromosomal localization (Protocol 1.7). Graphics may represent all spots at once or only those belonging to one chromosome (see Figure 1.1). The sensitivity of CGH depends on the purity of the tumor sample and of the quality of the DNA obtained.

The oligonucleotide aCGH protocol presented provides a highly sensitive and reproducible platform applicable to DNA isolated from both fresh and FFPE tissue. We do not present protocols on the preparation of the array slides, since these can be purchased commercially.

\section{PROTOCOL 1.1 DNA Extraction from Fresh or Frozen Tissue}

\section{Equipment and reagents}

- Wizard Genomic DNA Purification Kit (Promega, A1120), containing:

- EDTA/nuclei lysis solution

- proteinase $\mathrm{K}(20 \mathrm{mg} / \mathrm{ml})$

- RNase solution $(100 \mathrm{mg} / \mathrm{ml})$

- protein precipitation solution

- Phase lock gel (PLG, Eppendorf)

- Phenol solution (e.g. Sigma-Aldrich, P-4557)

- Chloroform

- Isopropanol

- Phenol/chloroform: $50 \%$ (v/v) phenol, $50 \%$ (v) chloroform

- TE: $10 \mathrm{mM}$ Tris- $\mathrm{HCl}$, pH 8.0, $1 \mathrm{mM}$ EDTA

- Ethanol (70\% (v/v) and $100 \%(\mathrm{v} / \mathrm{v})$, both ice-cold)

- Sodium acetate (3 M, pH 5.2). 


\section{Method}

1 To a $1.5 \mathrm{ml}$ microcentrifuge tube add:

- $0.5-1 \mathrm{~cm}^{3}$ of tissue;

- $600 \mu \mathrm{l}$ of EDTA/nuclei lysis solution;

- $17.5 \mu \mathrm{l}$ of proteinase $\mathrm{K}$.

2 Incubate overnight at $55^{\circ} \mathrm{C}$ with gentle shaking, or vortex the sample several times during the incubation.

3 Add $3 \mu$ l of RNase solution to the nuclear lysate and mix the sample by inverting the tube two to five times.

4 Incubate the mixture for $15-30 \mathrm{~min}$ at $37^{\circ} \mathrm{C}$.

5 Add $200 \mu$ l of protein precipitation solution to the sample and vortex vigorously. Chill the sample on ice for $10 \mathrm{~min}$.

6 Centrifuge at $20000 \mathrm{~g}$ for $15 \mathrm{~min}$ at room temperature to pellet the precipitated protein.

7 Carefully transfer the supernatant containing the DNA to a fresh $1.5 \mathrm{ml}$ microcentrifuge tube.

8 Add $600 \mu$ l of isopropanol (at room temperature).

9 Mix the solution by gently inverting until the white thread-like strands of DNA form a visible mass.

10 Centrifuge at $20000 \mathrm{~g}$ for $1 \mathrm{~min}$ at room temperature. The DNA will be visible as a small white pellet. Carefully aspirate supernatant by decanting the liquid. Air dry until no ethanol is visible.

11 Add $200 \mu$ l of TE to resuspend the DNA.

12 Pellet $2 \mathrm{ml}$ of PLG light by centrifuging at $12000-16000 \mathrm{~g}$ for $20-30 \mathrm{~s}$ at room temperature.

13 Add the $200 \mu$ l of DNA-containing TE to the $2 \mathrm{~mL} \mathrm{PLG} \mathrm{light} \mathrm{tube,} \mathrm{followed} \mathrm{by} 200 \mu \mathrm{l}$ of phenol-chloroform.

14 Mix the organic and the aqueous phases thoroughly by inversion. ${ }^{a}$

15 Centrifuge at $12000-16000 \mathrm{~g}$ for $5 \mathrm{~min}$ at room temperature to separate the phases. Transfer the upper layer/supernatant to a new $1.5 \mathrm{ml}$ microcentrifuge tube.

16 Add $200 \mu \mathrm{l}$ of chloroform directly to the above new $1.5 \mathrm{ml}$ microcentrifuge tube.

17 Mix thoroughly by inversion. ${ }^{a}$

18 Centrifuge at $12000-16000 \mathrm{~g}$ for $5 \mathrm{~min}$ at room temperature to separate the phases.

19 Transfer the aqueous solution (above the gel) to a new $1.5 \mathrm{ml}$ microcentrifuge tube.

20 Add $20 \mu \mathrm{l}$ of $3 \mathrm{M}$ sodium acetate and mix by inversion. 
21 Add $2.5 \times$ the total volume of $100 \%(\mathrm{v} / \mathrm{v})$ ethanol (ice cold). ${ }^{b}$

22 Centrifuge at $12000-16000 \mathrm{~g}$ for $15 \mathrm{~min}$ at room temperature.

23 Discard the supernatant and add $500 \mu \mathrm{l}$ of $70 \%(\mathrm{v} / \mathrm{v})$ ethanol (ice cold). Vortex the sample and centrifuge at $20000 \mathrm{~g}$ for $10-15 \mathrm{~min}$ at $4{ }^{\circ} \mathrm{C}$.

24 Discard the supernatant and allow the pellet to air dry until no ethanol is visible.

25 Resuspend the pellet in $100 \mu \mathrm{l}$ of TE or water.

\section{Notes}

${ }^{a}$ Do not vortex.

${ }^{b}$ After mixing, the DNA should come out of solution.

\section{PROTOCOL 1.2 DNA Extraction from FFPE Tissue}

\section{Equipment and reagents}

- Xylene (e.g. Merck - VEL, 90380)

- Methanol

- Ethanol $(100 \%(\mathrm{v} / \mathrm{v}), 96 \%(\mathrm{v} / \mathrm{v}), 70 \%(\mathrm{v} / \mathrm{v}))$

- QIAamp DNA Mini Kit 250 (Qiagen, 51306), or QIAamp DNA Micro Kit 50 (Qiagen, 56304) if the amount of tissue is limited (i.e. a biopsy)

- $\operatorname{NaSCN}$ (e.g. Sigma), 1 M

- Proteinase K (e.g. Roche), $20 \mathrm{mg} / \mathrm{ml}$

- RNase A (e.g. Roche), $100 \mathrm{mg} / \mathrm{ml}$

- Phosphate-buffered saline (PBS).

\section{Method $^{c}$}

1 Transfer two or three $50 \mu \mathrm{m}$ FFPE tissue sections into a microcentrifuge tube.

2 Incubate with $1 \mathrm{ml}$ of xylene for $7 \mathrm{~min}$ at room temperature, mixing a few times by vortexing.

3 Centrifuge at $14000 \mathrm{~g}$ for $5 \mathrm{~min}$ at room temperature and discard the supernatant.

4 Repeat steps 2 and 3 twice.

5 Incubate with $1 \mathrm{ml}$ of methanol for $5 \mathrm{~min}$ at room temperature, mixing a few times by vortexing.

6 Centrifuge at $14000 \mathrm{~g}$ for $5 \mathrm{~min}$ at room temperature and discard the supernatant.

7 Repeat steps 5 and 6 once 
8 Add $1 \mathrm{ml}$ of PBS, mixing a few times by vortexing.

9 Centrifuge at $14000 \mathrm{~g}$ for $5 \mathrm{~min}$ at room temperature and discard the supernatant.

10 Repeat steps 8 and 9 once.

11 Incubate with $1 \mathrm{ml}$ of $1 \mathrm{M} \mathrm{NaSCN}$ overnight at $38-40{ }^{\circ} \mathrm{C}$, mixing a few times by vortexing.

12 Centrifuge at $14000 \mathrm{~g}$ for $5 \mathrm{~min}$ at room temperature and discard the supernatant.

13 Wash the pellet three times with $1 \mathrm{ml}$ of PBS as in steps 11 and 12 .

14 Add $200 \mu$ l of Buffer ATL (QIAamp kit) and $20 \mu$ l of proteinase $K$, mixing a few times by vortexing.

15 Incubate at $50-60{ }^{\circ} \mathrm{C}$ for $60 \mathrm{~h}$, adding an extra $20 \mu \mathrm{l}$ of proteinase $\mathrm{K}$ every $12 \mathrm{~h}$.

16 Incubate with $40 \mu \mathrm{l}$ of RNase A for 2 min at room temperature, mixing a few times by vortexing.

17 Incubate with $400 \mu \mathrm{l}$ of Buffer AL (QIAamp kit) for 10 min at $65-75^{\circ} \mathrm{C}$, mixing a few times by vortexing.

18 Add $420 \mu$ l of $100 \%(v / v)$ ethanol and mix by vortexing thoroughly.

19 Transfer $600 \mu \mathrm{l}$ of the solution to a QIAamp centrifuge column.

20 Centrifuge at $2000 \mathrm{~g}$ for $1 \mathrm{~min}$ at room temperature and discard the flow through.

21 Repeat steps 19 and 20 until all the sample has been applied to the column.

22 Add $500 \mu$ l of Buffer AW1 (QIAamp kit) to the column.

23 Centrifuge at $2000 \mathrm{~g}$ for $1 \mathrm{~min}$ at room temperature and discard the flow through.

24 Add $500 \mu$ l of Buffer AW2 (QIAamp kit) to the column.

25 Centrifuge at $14000 \mathrm{~g}$ for $3 \mathrm{~min}$ at room temperature and discard the flow through.

26 Transfer the column to a fresh microcentrifuge tube (with a lid).

27 Elute the DNA from the column by adding $75 \mu \mathrm{l}$ of Buffer AE (QIAamp kit), preheated to $65-75^{\circ} \mathrm{C}$.

28 Leave at room temperature for $1 \mathrm{~min}$.

29 Centrifuge at $2000 \mathrm{~g}$ for $1 \mathrm{~min}$ at room temperature.

30 Discard the column and store the DNA at $2-8^{\circ} \mathrm{C}$.

\section{Notes}

${ }^{c}$ The protocol described is for the isolation of DNA from about $1 \mathrm{~cm}^{2}$ or larger size tissue sections using the QIAmp Mini kit. In the case of small-sized tissue sections (i.e. less than $0.5 \mathrm{~cm}^{2}$ ), extract DNA using the QIAmp Micro kit. The proteinase $\mathrm{K}$ volumes and incubation times may need to be adjusted, and the RNase treatment omitted. The quality of the DNA extracted from FFPE tissue may differ considerably. In general, older paraffin blocks yield DNA of worse quality. An important factor for preservation of DNA in FFPE tissue is the use of $\mathrm{pH} 7.0$ buffered formalin fixative before embedding in paraffin wax. 


\section{PROTOCOL 1.3 DNA Concentration Measurement Using Picogreen}

\section{Equipment and reagents}

- TE: $10 \mathrm{mM}$ Tris-HCl, pH 8.0, 0.1 mM EDTA

- PicoGreen dsDNA reagent(Molecular Probes) ${ }^{d}$

- Lambda DNA standards

- Recommended microtiter plates (immunoassay microplates - flat bottom; Dynex Immulux ${ }^{\mathrm{TM}}$ )

- Fluorescence plate reader

- Centrifuge for microtiter plates.

\section{${ }^{e}$ Method}

1 Prepare a series of $100 \mu \mathrm{l} /$ well lambda DNA standards, in duplicate, within a clean, 96-well plate as follows:

\begin{tabular}{ccc}
\hline Lamba DNA $(2 \mu \mathrm{g} / \mu \mathrm{l})$ & TE $(\mu \mathrm{l})$ & Final concentration \\
\hline $100 \mu \mathrm{l}$ & 0 & $100 \mathrm{ng} / \mu \mathrm{l}$ \\
$75 \mu \mathrm{l}$ & 25 & $750 \mathrm{pg} / \mu \mathrm{l}$ \\
$50 \mu \mathrm{l}$ & 50 & $500 \mathrm{pg} / \mu \mathrm{l}$ \\
$25 \mu \mathrm{l}$ & 75 & $250 \mathrm{pg} / \mu \mathrm{l}$ \\
$10 \mu \mathrm{l}$ & 90 & $100 \mathrm{pg} / \mu \mathrm{l}$ \\
$5 \mu \mathrm{l}$ & 95 & $50 \mathrm{pg} / \mu \mathrm{l}$ \\
$0 \mu \mathrm{l}$ & 100 & $0 \mathrm{pg} / \mu \mathrm{l}$ \\
\hline
\end{tabular}

2 For each DNA sample, prepare duplicate dilutions of $2 \mu \mathrm{l}$ of DNA with $98 \mu \mathrm{L}$ of TE.

3 For each DNA sample dilution, prepare $100 \mu$ l of Picogreen ${ }^{d}$ reagent by diluting Picogreen 200-fold in TE.

4 Add $100 \mu \mathrm{l}$ of diluted Picogreen reagent to each diluted DNA sample and mix by pipetting up and down.

5 Centrifuge the microtitre plate at $250 \mathrm{~g}$ for $1 \mathrm{~min}$ to remove possible bubbles.

6 Read in a plate reader (excitation $485 \mathrm{~nm}$, emission $538 \mathrm{~nm}$ ).

7 Calculate concentrations from the standard curve using the plate reader software package.

\section{Notes}

${ }^{d}$ Avoid excess exposure to light since the dye is light sensitive.

${ }^{e}$ For quantitation of DNA from FFPE tissue for SNP arrays, the use of Picogreen gives more reliable estimates than measurement of $A_{260} \mathrm{~nm}$ using a spectrophotometer [12]. 


\section{PROTOCOL 1.4 DNA Quality Control PCR}

\section{Equipment and reagents}

- Primer stocks (100 $\mu \mathrm{M})$ :

- RS2032018 (150 bp)

- primer 1: 5'-GTGTCTCCCTTCCCACTCAA-3'

- primer 2: 5'-AGCCCACCTACCTTGGAAAG-3'

—AP000555 (PRKM1, 255 bp)

- primer 3: 5'-TGGCTGATCTATGTCCCTGA-3'

- primer 4: 5'-GCTCAGTTGTTTTGTGGGTAAG-3'

- AC008575 (APC, 511 bp)

- primer 5 GCTCAGACACCCAAAAGTCC

- primer 6: CATTCCCATTGTCATTTTCC

- Polymerase chain reactions (PCRs) reaction buffer II without $\mathrm{MgCl}_{2}$ (Applera)

- Amplitaq gold DNA polymerase (5 units/ $\mu$ l Applera).

\section{Method}

1 Prepare a primer working solution mix containing $20 \mathrm{pm} / \mu \mathrm{l}$ of primers 1 and 2, and $10 \mathrm{pm} / \mu \mathrm{l}$ for primers $3-6 .{ }^{f}$

2 Prepare a $10 \mu \mathrm{l}$ reaction by mixing the following:

- $0.25 \mu$ l of primer mix

- $1.0 \mu \mathrm{l}$ of $10 \times \mathrm{PCR}$ reaction buffer II without $\mathrm{MgCl}_{2}$

- $0.2 \mu \mathrm{l}$ of $4 \times 10 \mathrm{mM}$ dNTPs

- $1.0 \mu \mathrm{l}$ of $25 \mathrm{mM} \mathrm{MgCl}$

- $2.0 \mu$ l of template DNA $(1-250 \mathrm{ng})^{g, h}$

- $0.1 \mu \mathrm{l}$ of Amplitaq gold DNA polymerase

- $5.45 \mu \mathrm{l}$ of water.

3 Thermocycle as follows:

- $96^{\circ} \mathrm{C}, 10 \mathrm{~min}$

- $\left(94^{\circ} \mathrm{C}, 30 \mathrm{~s} ; 55^{\circ} \mathrm{C}, 30 \mathrm{~s} ; 72^{\circ} \mathrm{C}, 1 \mathrm{~min}\right) \times 35$

- $72{ }^{\circ} \mathrm{C}, 5 \mathrm{~min}$.

4 Analyze each PCR product by $2 \%(w / v)$ Tris-acetate-EDTA agarose gel electrophoresis. Compare the sizes of amplified products against molecular weight marker standards. ${ }^{i}$ 


\section{Notes}

${ }^{f}$ The multiplex PCR amplifies three amplicons, one each of of $150 \mathrm{bp}, 255 \mathrm{bp}$ and $511 \mathrm{bp}$. This method is comparable to the van Beers method [38].

gUse $10 \mathrm{ng}$ of genomic DNA prepared from freshly frozen tissue as a control.

${ }^{h}$ If the DNA concentration (see Protocol 1.9) is higher than $5 \mathrm{ng} / \mu \mathrm{l}$ it can be diluted in water. ${ }^{i}$ The 150 and $255 \mathrm{bp}$ amplicons have to amplify for a DNA template considered to be suitable for aCGH.

\section{PROTOCOL 1.5 Labeling of DNA for Oligonucleotide aCGH}

\section{Equipment and reagents}

- BioPrime DNA labeling system (Invitrogen, 18094-011), containing:

$-2.5 \times$ random primers solution

- Klenow fragment of DNA polymerase I $(40 \mathrm{U} / \mu \mathrm{l})$; keep on ice at all times, or preferably use $\mathrm{a}-20^{\circ} \mathrm{C}$ labcooler when taking in and out of the freezer.

- Cy3-labeled dCTP (e.g. Amersham Biosciences/Perkin Elmer)

- Cy5-labeled dCTP (e.g. Amersham Biosciences/Perkin Elmer)

- ProbeQuant G-50 Micro Columns (Amersham Biosciences)

- dNTP mixture; for $200 \mu \mathrm{l}$ mix:

$-4 \mu \mathrm{l}$ of $100 \mathrm{mM}$ dATP

$-4 \mu \mathrm{l}$ of $100 \mathrm{mM}$ dGTP

$-4 \mu \mathrm{l}$ of $100 \mathrm{mM}$ dTTP

$-1 \mu \mathrm{l}$ of $100 \mathrm{mM} \mathrm{dCTP}$

$-2 \mu \mathrm{l}$ of $1 \mathrm{M}$ Tris $-\mathrm{HCl}, \mathrm{pH} 7.6$

$-0.4 \mu \mathrm{l}$ of $0.5 \mathrm{M}$ EDTA, $\mathrm{pH} 8.0$

$-184.6 \mu \mathrm{l}$ of water.

\section{Method}

1 In a PCR tube, mix $300 \mathrm{ng}^{j}$ of genomic DNA and $20 \mu \mathrm{l}$ of $2.5 \times$ Random Primers solution. Adjust the volume to $42 \mu \mathrm{l}$ with water.

2 Denature the DNA mixture in a PCR machine at $100^{\circ} \mathrm{C}$ for $10 \mathrm{~min}$ and immediately transfer to an ice/water bath for 2-5 min. Briefly centrifuge and put back on ice.

3 While maintaining on ice, add $5 \mu \mathrm{l}$ of dNTP mixture, $2 \mu \mathrm{l}$ of Cy3 (test) or Cy 5 (ref) labeled dCTPk and $1 \mu$ l of Klenow DNA polymerase.

$4 \mathrm{Mix}$ well and incubate at $37^{\circ} \mathrm{C}$ (in PCR machine) for $14 \mathrm{~h}$, and then maintain at $4^{\circ} \mathrm{C}$. 
5 Prepare a Probe-Quant G-50 column for removal of uncoupled dye material as follows:

- resuspend the resin in the column by vortexing;

- loosen the cap one-fourth turn and snap off the bottom closure;

- place the column in a $1.5 \mathrm{ml}$ microcentrifuge tube and centrifuge at $735 \mathrm{~g}$ for 1 min. !

6 Place the column into a fresh $1.5 \mathrm{ml}$ tube and slowly apply $50 \mu \mathrm{l}$ of the sample to the top center of the resin, being careful not to disturb the resin bed.

7 Centrifuge the column at $735 \mathrm{~g}$ for $2 \mathrm{~min}$. The purified sample is collected at the bottom of the support tube.

8 Discard the column and store the purified and labeled sample ${ }^{m}$ in the dark until use on the same day, or alternatively store at $-20^{\circ} \mathrm{C}$ for a maximum of 10 days.

\section{Notes}

${ }^{j}$ For paraffin-embedded tissue, $600 \mathrm{ng}$ of test and reference DNA samples should be used. We experienced that reference DNA prepared from either blood or FFPE 'normal tissue' can give equally good results.

${ }^{k}$ Test and reference DNA can be labeled with either Cy3 or Cy5.

'Start the timer and microcentrifuge simultaneously to ensure that the total centrifugation time does not exceed $1 \mathrm{~min}$.

${ }^{m}$ It is not necessary to exactly quantify the labeled DNA or the degree of Cy5/Cy3-dCTP incorporation, because in the data analysis a normalization of the Cy5/Cy3 channels takes place.

\section{PROTOCOL 1.6 Hybridization}

\section{Equipment and reagents}

- Blocking solution: ${ }^{n} 0.1 \mathrm{M}$ Tris, $50 \mathrm{mM}$ ethanolamine, $\mathrm{pH}$ 9.0: dissolve $6.055 \mathrm{~g}$ of Trizma base and $7.88 \mathrm{~g}$ of Trizma- $\mathrm{HCl}$ in $900 \mathrm{ml}$ of water. Add $3 \mathrm{ml}$ of ethanolamine (Sigma-Aldrich Chemie B.V. Zwijndrecht, Netherlands) and mix thoroughly. Adjust the $\mathrm{pH}$ to 9.0 using $6 \mathrm{~N} \mathrm{HCl}$. Adjust the final volume to $1 \mathrm{l}$ with water.

- $20 \times$ SSC, pH 7.0 (e.g. Sigma) and dilutions in water $(0.2 \times, 0.1 \times$ and $0.01 \times$ SSC).

- $20 \%$ (w/v) SDS solution: for preparation of $100 \mathrm{ml}$, dissolve $20 \mathrm{~g}$ of sodium dodecyl sulfate in $90 \mathrm{ml}$ of water. Adjust the final volume to $100 \mathrm{ml}$.

- Wash solution: $4 \times$ SSC, $0.1 \%(w / v)$ SDS: $200 \mathrm{ml}$ of $20 \times$ SSC, $10 \mathrm{ml}$ of $10 \%(w / v)$ SDS, adjust the final volume to $1 \mathrm{l}$ with water.

- Human Cot-1 DNA, $1 \mu \mathrm{g} / \mu \mathrm{l}$ (e.g. Invitrogen).

- Yeast tRNA, $100 \mu \mathrm{g} / \mu \mathrm{l}$ (e.g. Invitrogen). 
- Master mix - $14.3 \%(\mathrm{w} / \mathrm{v})$ dextran sulfate, $50 \%(\mathrm{v} / \mathrm{v})$ formamide, $2.9 \times$ SSC, $\mathrm{pH} 7.0$ : Combine $1 \mathrm{~g}$ of dextran sulfate (USB), $3.5 \mathrm{ml}$ of redistilled formamide (Invitrogen; store at $\left.-20^{\circ} \mathrm{C}\right), 2.5 \mathrm{ml}$ of water and $1 \mathrm{ml}$ of $20 \times$ SSC. Gently shake for several hours to dissolve the dextran sulfate and store aliquoted at $-20^{\circ} \mathrm{C}$.

- Washing buffer: $50 \%(\mathrm{v} / \mathrm{v})$ formamide, $2 \times$ SSC, $\mathrm{pH} 7.0$.

- PN buffer: $0.1 \mathrm{M} \mathrm{Na}_{2} \mathrm{HPO}_{4} / \mathrm{NaH}_{2} \mathrm{PO}_{4}$, pH 8.0, 0.1\% (v/v) Igepal CA630 (e.g. Sigma).

- GeneTAC/HybArray12 hybstation (Genomic Solutions/Perkin Elmer).

\section{Method}

1 Add 0.01 volume of $10 \%$ (w/v) SDS to the blocking solution (final concentration of $0.1 \%$ (w/v) SDS) and pre-warm at $50^{\circ} \mathrm{C}$.

2 Place an oligonucleotide microarray slide in a slide rack and block residual reactive groups by incubating in pre-warmed blocking solution at $50^{\circ} \mathrm{C}$ for $15 \mathrm{~min} .{ }^{\circ}$

3 Rinse the slide twice with water.

4 Wash the slide with wash solution (pre-warmed to $50^{\circ} \mathrm{C}$ ) for $15-60 \min ^{p}$

5 Rinse briefly with water, but do not allow the slide to dry prior to centrifugation.

6 Place the slide in a $50 \mathrm{ml}$ tube and centrifuge at $200 \mathrm{~g}$ for $3 \mathrm{~min}$ to dry.

7 Use a slide for hybridization within 1 week.

8 In a $1.5 \mathrm{ml}$ tube, mix: $50 \mu \mathrm{l}$ of Cy3-labeled test ${ }^{q}$ DNA, $50 \mu \mathrm{l}$ of Cy5-labeled reference DNA and $10 \mu \mathrm{l}$ of Cot-1 DNA.'

9 Add $11 \mu \mathrm{l}$ of $3 \mathrm{M}$ sodium acetate, pH 5.2 (0.1 volume) and $300 \mu$ l of ice-cold $100 \%(\mathrm{v} / \mathrm{v})$ ethanol, mix the solution by inversion and collect the DNA by centrifugation at $20000 \mathrm{~g}$ for 30 min at $4^{\circ} \mathrm{C}$.

10 Remove the supernatant with a pipette and air-dry the pellet for 5-10 min until no ethanol is visible. Carefully dissolve the pellet in $13 \mu \mathrm{l}$ of yeast tRNA and $26 \mu \mathrm{l}$ of $20 \%$ $(w / v)$ SDS. Leave at room temperature for at least $15 \mathrm{~min}$.

11 Add $91 \mu$ l of master mix and mix gently.

12 Denature the hybridization solution at $73{ }^{\circ} \mathrm{C}$ for $10 \mathrm{~min}$, and incubate at $37^{\circ} \mathrm{C}$ for $60 \mathrm{~min}$ to allow the Cot-1 DNA to block repetitive sequences.

13 Store the following programs named 'CGH.hyb' on the hybstation':

(a) introduce hybridization solution, temperature $37^{\circ} \mathrm{C}$

(b) set slide temperature: temperature: $37^{\circ} \mathrm{C}$; time: 38 hours : 00 minutes : 00 seconds, agitate: Yes

(c) wash slides (washing buffer): six cycles, source 1 , waste 2 at $36^{\circ} \mathrm{C}$, flow for $10 \mathrm{~s}$, hold for $20 \mathrm{~s}$

(d) wash slides (PN buffer): two cycles, source 2, waste 1 at $25^{\circ} \mathrm{C}$, flow for $10 \mathrm{~s}$, hold for $20 \mathrm{~s}$ 
(e) wash slides $(0.2 \times \mathrm{SSC})$ : two cycles, source 3 , waste 1 at $25^{\circ} \mathrm{C}$, flow for $10 \mathrm{~s}$, hold for $20 \mathrm{~s}$

(f) wash slides $(0.1 \times \mathrm{SSC})$ : two cycles, source 4 , waste 1 at $25^{\circ} \mathrm{C}$, flow for $10 \mathrm{~s}$, hold for $20 \mathrm{~s}$.

14 Assemble up to six hybridization units (two slides per unit): insert rubber 0-rings in the covers and put the slides on the black bottom plate. Make sure the slides are in the proper orientation with the printed side up.

15 Introduce the unit into the hybstation, press unit down with one hand while tightening the screw with the other.

16 Insert plugs into the sample ports and the waste tubes into the corresponding wash bottles.

17 On the touch screen subsequently press: start a run, from floppy, CGH.hyb, load, the positions of the slides you want to use, start, continue (the hybstation starts to warm up the slides).

18 When the hybstation is ready (visible on screen by indication of the module you have to start) apply hyb mix:

(a) press Probe to add the hyb mix for the selected slide

(b) check if a mark on the screen appears

(c) take the plug out and inject the hyb mix by pipetting it slowly into the port using a $200 \mu \mathrm{l}$ pipette

(d) press the Finished control (check mark) and replace the plug

(e) repeat this for the next slide

(f) press the Finished control for the selected slide

(g) press the Finished control for the module

(h) repeat this for the selected module(s).

19 Take slides out after $38 \mathrm{~h}$ and put them in $0.01 \times$ SSC.

20 Place each slide in a $50 \mathrm{ml}$ tube and centrifuge at $200 \mathrm{~g}$ for 3 min to dry.

21 Immediately scan slides in a microarray scanner.

22 Cleaning the hybstation: ${ }^{u}$

23 Reassemble all used hybridization units with dummy slides and introduce them into the hybstation.

24 Insert plugs into all sample ports and place all tubes in a bottle of water.

25 On the touch screen subsequently press: maintenance, Machine Cleaning Cycle, the positions of the slides you used, continue.

26 When cleaning is finished, take out the hybridization units, rinse with water (never use ethanol) especially the sample port and dry the unit with the air pistol. 


\section{Notes}

${ }^{n}$ This blocking solution is specific to the blocking of CodeLink ${ }^{\mathrm{TM}}$ slides (SurModics Inc) on which amino linker-containing oligonucleotides (dissolved at $10 \mu \mathrm{M}$ in $50 \mathrm{mM}$ sodium phosphate buffer $\mathrm{pH}$ 8.5) are spotted.

${ }^{o}$ Extend to $30 \mathrm{~min}$ if the blocking solution is not pre-warmed, but do not exceed $1 \mathrm{~h}$.

${ }^{p}$ Use at least $10 \mathrm{ml}$ of wash solution per slide.

${ }^{q}$ Test and reference DNA can be labeled with either Cy3 or Cy5.

${ }^{r}$ If many experiments are planned, we recommend ordering a large batch of Cot-1 DNA from the same lot.

${ }^{\text {s}}$ Take care to prevent foam formation due to the SDS.

${ }^{t}$ Alternative manual protocol for hybridization and washing: cut off the large end of a $200 \mu \mathrm{l}$ pipette tip to fit on a $5 \mathrm{ml}$ syringe and fill the syringe with rubber cement (Ross). Apply the rubber cement closely around an array. Apply a second or third layer of rubber cement thickly. Apply the hybridization mixture to the array and incubate the slide assembly in a closed incubation chamber over two nights at $37^{\circ} \mathrm{C}$ on a rocking table. Following hybridization, disassemble the slide assembly and rinse the hybridization solution from the slide in a room temperature stream of PN buffer. Wash the array in wash buffer for $10-15 \mathrm{~min}$ at $45^{\circ} \mathrm{C}$, followed by a $10-15$ min room temperature wash in PN buffer. Carefully remove the rubber cement (do not let the array dry) with tweezers/forceps, wash the array sequentially with $0.2 \times$ SSC and $0.1 \times$ SSC and centrifuge dry (250g, $3 \mathrm{~min})$.

"Cleaning the hybstation after each hybridization is essential to maintain proper functioning of the equipment.

\section{PROTOCOL 1.7 Scanning and Creation of a Copy Number Profile}

\section{Equipment and reagents}

- High-resolution laser scanner, or imager equipped to detect Cy3 and Cy5 dyes, including software to acquire images (e.g. Microarray Scanner G2505B, Agilent Technologies)

- Feature-extraction software (e.g. Bluefuse 3.2 (BF), BlueGnome Ltd, UK)

- Gene array list (GAL-file, or equivalent) - created by the microarray printer software using the oligonucleotide plate content lists provided by the supplier of the oligo library

- Position list: a file, containing the relative positions of the oligonucleotides in the genome under investigation, provided by the supplier of the oligo library, or created by mapping the oligonucleotide sequences onto the genome concerned

- Software which calculates ratios, links the genomic position of the oligonucleotide to the experimental ratios and draws a profile (e.g. Microsoft Excel, or dedicated software such as $\mathrm{BF})$. 


\section{Method}

1 Allow scanner lasers to warm up for 5 min before starting.

2 Scan the microarray at $10 \mu \mathrm{m}$ scanning resolution according to the manufacturer's protocol.

3 Store scans from both channels as separate TIFF images

4 Perform automated spot finding, using the information from the GAL-file to position the array grid over each image.

5 Perform automated spot exclusion. ${ }^{v}$

6 Perform automated linking of the spot ratios to the genomic positions of the corresponding oligonucleotides (using the information from the position file).

7 Perform global mode normalization. ${ }^{w}$

8 Draw the genomic profile (automated in $\mathrm{BF}$ ): order normalized ratios by chromosomal mapping and display in a graph. ${ }^{x}$

\section{Notes}

'We suggest excluding spots that have a 'confidence value' lower than 0.1 , or a 'quality flag' lower than 1, which will further diminish outliers. These confidence values are calculated in a proprietary manner by the BF feature extraction software.

${ }^{\text {w}}$ Avoid block normalization (normalization per printed block of spots on the array slide, which can be performed by either median, or intensity-dependent lowess), because this may compress the profile. Mode normalization is used to set the 'normal' level and is preferred over mean or median normalization, as it is more accurate since it ignores the ratios generated by gains, amplifications and deletions. Block normalization is sometimes used to suppress noise, although its suitability may depend on the type of sample analyzed; that is, for samples showing few aberrations, block normalization may help to suppress noise, but is not recommended for samples with multiple chromosomal aberrations (e.g. tumor samples).

${ }^{x}$ For more sophisticated analysis procedures and to 'call' the actual gains, losses and amplifications, we recommend the use of more dedicated software, such as the freeware CGH call [14].

\subsubsection{SNP aCGH}

The recently developed high-density SNP microarrays were originally developed for high-throughput genotyping for linkage analysis and association studies. These arrays have additionally proven useful to measure both genomic copy-number variations and loss of heterozygosity ( $\mathrm{LOH})$; that is, SNP aCGH. The ability of SNP aCGH, unlike conventional $\mathrm{CGH}$, to detect copy-neutral genetic anomalies offers the benefit of detecting copy-neutral LOH [15]. Moreover, the combination of copy number abnormalities and LOH status with the parental origin of the aberrant allele can possibly be associated with the predisposition to hereditary cancer. Successful use of SNP aCGH has been reported for several cancers, such as breast, colorectal and lung cancer [16-19]. While the current 
high-density SNP arrays can interrogate more than a million SNPs, these arrays cannot (yet) be used reliably with DNA from FFPE tissue. This is due to the fragmented nature of the DNA isolated from FFPE tissue. For this purpose, current arrays are restricted to $6000-10000$ features.

Different methodologies and types of commercially available SNP arrays exist. These consist of either locus-specific arrays of oligonucleotides (Genechips) or of arrays with universal capture oligonucleotide on beads that are randomly assembled on arrays and subsequently decoded (Beadarrays). Genechips can detect up to 250000 SNPs on a single chip. For each SNP, a set of locus-specific oligonucleotides is synthesized on the array. The sample is prepared according to a whole-genome sampling assay [20]. After restriction enzyme digestion of high molecular weight genomic DNA and ligation of a common adaptor, the DNA is amplified in a single-primer PCR and hybridized to a locus-specific array [21]. For Infinium arrays, genomic DNA is whole-genome amplified, subsequently fragmented, and denatured DNA is hybridized to a locus-specific array. An allele-specific primer extension assay on the array is followed by staining and scanning of the arrays using standard immunohistochemical detection methods. Currently these arrays can detect over a million SNPs on a single array [22]. Goldengate genotyping makes use of a multiplex mixture of probes for 96, 384, 768 or 1536 SNPs per array [23]. For each SNP, a combination of allele-specific and locus-specific primers is annealed to the SNP locus, the primers are tailed with common forward and reverse primers and a complementary universal capture probe to the locus-specific primer. Subsequent allele-specific primer-extension, followed by ligation, generates an allele-specific artificial PCR template. This template is then PCR-amplified and labeled. After hybridization to an array of universal-capture probes, the array is scanned in two colors, representing the two alleles of an SNP. Molecular-inversion probe (MIP) genotyping utilizes a pool of circularizable locus-specific probes with a multiplexing degree of over 10000 SNPs per array. The 5' and 3' ends of each probe anneal upstream and downstream of the SNP. The 1 bp gap is filled; subsequent ligation seals the nick and generates a circular probe. Restriction digestion then releases the circularized probe and the resultant product is PCR-amplified using common primers [24]. The four nucleotide reactions are labeled in different colors and pooled. Subsequently, the pool is hybridized to an array of universal-capture probes and the four colors are read out in a scanner. Whereas the high-density Genechip and Infinium arrays are designed for use with high-quality genomic DNA, both the Goldengate and the MIP assay can be used to detect LOH and copy number changes in FFPE tissue [25, 26].

SNP aCGH collects both intensity and allelic information from a sample. To extract profiles of $\mathrm{LOH}$ and copy number abnormalities, different methods and algorithms have been reported [13,27-30]. For the interpretation of $\mathrm{LOH}$ and copy number abnormalities, specifically for the Goldengate assay, a limited or no method was available. Therefore, to interpret the Beadarray data an R-package BeadArraySNP was developed. The package deals with the normalization of the allele-specific signal intensities and the representation of the copy number and LOH profiles [25].

Here we describe the use of the GoldenGate assay and Beadarrays to generate high-resolution copy number profiles and LOH using DNA isolated from FFPE tissue (Protocol 1.8). We do not present Illumina protocols, since this is a commercial platform. The most recent version of the protocol (user card) can be obtained through www .illumina.com. 


\section{PROTOCOL 1.8 Data Analysis of Illumina SNP Beadarray Experiments}

\section{Equipment and reagents}

- Illumina BeadScan software for genotyping and the Bioconductor (www.bioconductor.org) BeadarraySNP package [25]

- Quantile smoothing software [31].

\section{Methody}

1 Perform an Illumina GoldenGate ${ }^{T M}$ assay, ${ }^{y}$ according to the protocol supplied by Illumina, using $1 \mu \mathrm{g}$ of activated DNA (isolated from FFPE tissue) dissolved in 60-100 $\mu \mathrm{l}$ of RS1 buffer.

$2 \mathrm{Scan}^{z}$ the Illumina arrays using the Illumina BeadScan software, ${ }^{a a}$ creating (by default) the following types of files for each of the samples on the array:

- locs: locations of beads on the array

- idat: summarized intensity information (binary format)

- XML: scanner settings.

3 Adapt the Settings. $\mathrm{xm}^{b b}$ within the beadstudio directory in order to produce the additional file types.

$<$ SavePerBeadFiles $>$ true $<\backslash$ SavePerBeadFiles $>$

$<$ SaveEIFFiles $>$ false $<\backslash$ SaveEIFFiles $>$

$<$ SaveTextFiles $>$ true $<\backslash$ SaveTextFiles $>$

$<$ CompressImages $>$ true $<\backslash$ CompressImages $>$

$<$ ExcludeOutliers $>$ true $<\backslash$ ExcludeOutliers $>$

$<$ IncludeXY $>$ true $<\backslash$ IncludeXY $>$

4 Perform the genotyping of the scanned images using the GenCall software, ${ }^{c c}$ producing the following types of files for each experiment. ${ }^{d d}$

5 *-OPA_LocusByDNA_*.csv: genotyping and quality scores (one sample per row):

- *-OPA_LocusByDNA_*DNA_Report.csv: summary of allele frequencies for each sample

- *-OPA_LocusByDNA_*Final.csv: genotyping and quality scores (each probe and sample appear on a separate row)

- *-OPA_LocusByDNA_*Locus_Report.csv: quality index summaries for all probes.

6 Begin copy number analysis ${ }^{e e}$ by defining the samples in a sample sheet.ff Calculate the copy number values for all the samples in the experiment using the function standardNormalization().

7 Plot the raw and smoothed copy number data using the Quantile smoothing software. ${ }^{g g}$ 
8 Use the 50th percentiles (displayed on the plots as dotted lines; see Figure 1.2) to guide identification of gains and losses. ${ }^{\text {hh }}$
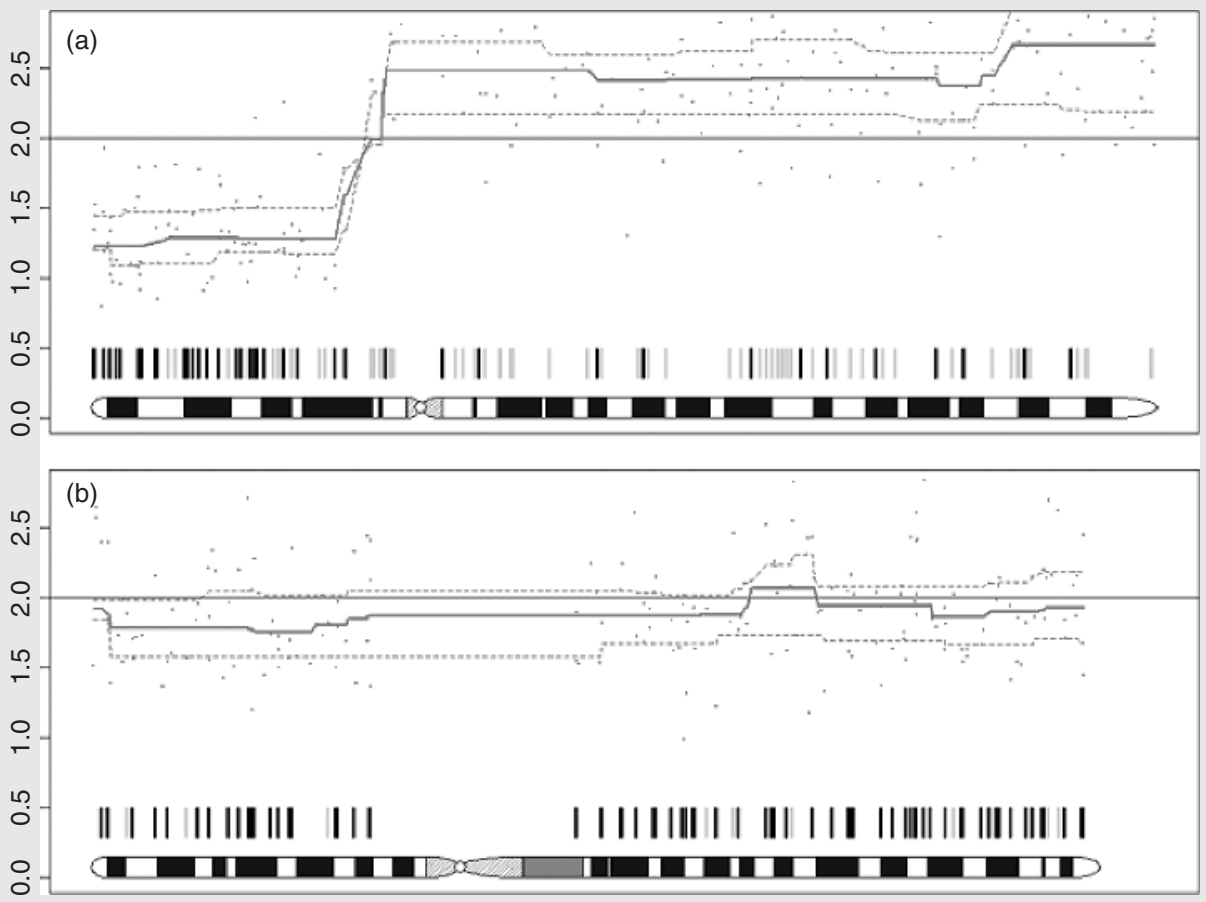

Figure 1.2 Chromosome view output of BeadArraySNP showing examples of a colorectal carcinoma. (a) Chromosome 8 with physical loss at the p-arm and gain at the q-arm. (b) An example of $\mathrm{LOH}$ without a copy number change on chromosome 9. Each red dot indicates the normalized individual SNP signal; the solid red lines show the smoothed copy number with the 25th and 75th percentile interval marked with the dashed red lines. The gray vertical bars above the ideogram show the heterozygous SNPs in the normal sample that retained heterozygosity in the paired tumor. Black vertical bars show $\mathrm{LOH}$; that is, heterozygous in the normal and homozygous in the tumor.

\section{Notes}

${ }^{y}$ Twelve tumor:normal pairs (24 samples) can be profiled using four pools of approximately 1500 SNPs (collectively referred to as the linkage panel). The SNPS are hybridized to sentrix arrays, a matrix of 96 arrays, each detecting about 1500 SNPs. Thus, for each sample, four arrays of approximately 1500 SNPs each are hybridized and subsequently combined to yield around 6000 genotypes. Alternatively, a genome-wide cancer SNP panel, or custom SNP panels of 1536, 768 or 384 SNPs, can be typed.

${ }^{z}$ The allele-specific data obtained from Illumina SNP-arrays can be used to perform both genotyping and copy number analysis. Although the Illumina software for genotyping performs satisfactorily in most cases, we have found that there is room for improvement in performing 
copy number analysis, in particular for the GoldenGate assay with fewer SNPs (6000 SNPs) compared with 100000 or 317000 SNP Infinium arrays.

${ }^{a a}$ This software can identify the individual beads and measure the intensity of each bead. In general, it is useful to organize the files created by BeadScan by putting them into separate subdirectories for each experiment.

${ }^{b b}$ These settings also create the following files: tiff: scanned image of sample; csv: summary values per probe - intensity, standard deviation, number of beads; txt: values for each bead intensity, position on tif.

${ }^{c c}$ Illumina provides two software packages that can perform genotyping on the scanned images. Gencall was the original application for genotyping and was followed by BeadStudio, which is an integrated package for performing all kinds of data analysis for Illumina arrays. The algorithm for genotyping differs between the packages. We prefer to use the results of GenCall as the input for copy number analysis. If genotyping is performed with the Illumina Gencall software then the csv files are needed to obtain copy number values.

${ }^{d d}$ Beadstudio produces a report file with a specifiable number of result fields. For the copy number analysis the following fields are needed: GC Score Allele1 - AB Allele2 - AB GT Score X Raw $Y$ Raw. The report file will contain the chosen values for each sample and probe.

${ }^{e e}$ This calculation consists of three stages: normalizeBetweenAlleles.SNP() Performs quantile normalization between both colors of a sample. This is allowed because the frequencies of both alleles throughout a sample are nearly identical in practice. This action also neutralizes any dye bias. normalizeWithinArrays.SNP() scales each sample using the median of the high-quality heterozygous SNPs as the normalization factor. Genomic regions that show copy number alterations are likely to show $\mathrm{LOH}$, or are harder to genotype leading to a decrease quality score of the call. normalizeLoci.SNP() scales each probe using the normal samples in the experiment, assuming that these samples are diploid, and have a copy number of two.

ff This can be the file produced by the Illumina genotyping software, but it is useful to include more information on the individual samples here; for example, experimental groups, normal/tumor tissue. The format for these data is explained in detail in the help pages for the package. The data quality should be checked. The overview of average intensities for both channels as laid out on the physical device has proved helpful to detect technical anomalies. For the GoldenGate assay both channels should have an average intensity above 1250 .

${ }^{g}$ Various plots of raw or smoothed copy number data can be obtained using the Quantile smoothing software, such as: smoothed intensities from all chromosomes for a number of samples, all samples in an experiment indicating regions of gain, loss and $\mathrm{LOH}$, for individual chromosomes, or a BAC-array-like plot for each sample in an experiment.

${ }^{h h} \mathrm{~A}$ gain is called where the 25th percentile line exceeds the $2 \mathrm{~N}$ line and a loss is called where the 75th percentile is below the diploid line.

\subsubsection{Multiple ligation-dependent probe amplification (MLPA)}

The MLPA technique was first described by Schouten et al. [7] in 2002 and has become a rapidly growing technique used in the detection of aberrations in genes related to various diseases. MLPA is a multiplex technique for determining copy numbers of genomic DNA sequences [32] and promoter methylation status [33], as well as mRNA profiling [34]. While genomic profiling is becoming increasingly important in both the research and diagnostic setting, routine detection methods for exon deletions and duplications are still lacking. 
To date, MLPA technology has shown its applicability in the research setting through several studies. These include detection of trisomies [35], Duchene and Becker muscular dystrophy [36], centrifugal muscular dystrophy and also detection of deletions and duplications of one or more exons of the BRCAI [37] and the MLHI /MSH2 genes [32]. However, the protocols described in this chapter are robust and specific enough to be used as a routine diagnostic assay.

MLPA is easy to perform and relatively cheap. Up to 96 samples can be handled simultaneously and results can be obtained within $24 \mathrm{~h}$. The required apparatus for MLPA (a thermocycler and sequencing type electrophoresis equipment) is present in most molecular biology laboratories. Probe target sequences are small (50-70 nucleotides), meaning that MLPA can be applied to partially degraded DNA, such as FFPE tissue DNA, or free fetal DNA obtained from maternal plasma. MLPA reactions are more sensitive to contaminants, often present in DNA samples extracted from FFPE tissues, than ordinary PCRs. Developing new MLPA probe mixes is complicated, expensive and time consuming. Each probe requires the design and preparation of a phage M13 clone, the purification of its single stranded DNA and digestion with expensive restriction endonucleases. For research purposes, it is possible to design a small number of completely synthetic probes, resulting in amplification products with lengths varying between 100 and 130 nucleotides.

MLPA is an approach based on the PCR technique, and is sufficiently sensitive, reproducible and sequence-specific to allow the relative quantification of up to 50 different targets simultaneously. In MLPA, probes and not sample nucleic acids are subject to amplification and quantification. MLPA probes consist of one short synthetic oligonucleotide and one M13-derived, long probe oligonucleotide, which hybridize to adjacent sites of the target sequence. The short probe contains a target-specific sequence (21-30 nucleotides) and a 19 nucleotide sequence at the $5^{\prime}$ end which is identical to the sequence of a labeled PCR primer. The long MLPA probe contains 24-43 nucleotides of target-specific sequence at the $5^{\prime}$ phosphorylated end, a 36 nucleotide sequence that contains the complement of an unlabeled PCR primer at the $3^{\prime}$ end, and a stuffer sequence of variable length in between. This variable-length fragment gives each complete probe the necessary size difference for detection and quantification using capillary gel electrophoresis [7]. Hybridized probe oligonucleotides are then ligated by a specific ligase enzyme, but only when both probes are stably hybridized to adjacent sites of the target sequence, permitting subsequent amplification (Protocol 1.9; see Figure 1.3).

MLPA probes are identified after capillary separation by size, using a selected size standard for the size calling procedure (Protocol 1.10). The relative MLPA probe signals (fluorescent units) reflect the relative copy number of the target sequence. An indication of the DNA input in the performed MLPA reaction may be obtained by examining the dosage quotient (DQ) control fragments, fragments whose lengths always co-vary and which are present in all MLPA kits. The signals of these fragments will be prominent if the amount of sample DNA is very low. By contrast, the fifth control band of 92 nucleotides is ligation dependent and should have a signal similar to most other MLPA amplification products. Visual inspection of the peak pattern of a patient sample superimposed over a peak pattern of a reference run can be used to analyze few sample numbers. Analyzing a larger sample series, more complex diseases and MLPA runs performed with miscellaneous sample types and quality require exportation of the peak signals and reliable normalization methods (Protocol 1.11).

To date, more than 150 MLPA applications are available, and this number is still growing rapidly. MLPA kits for the most common hereditary genetic disorders are already available, 
1. Denaturation \& hybridization

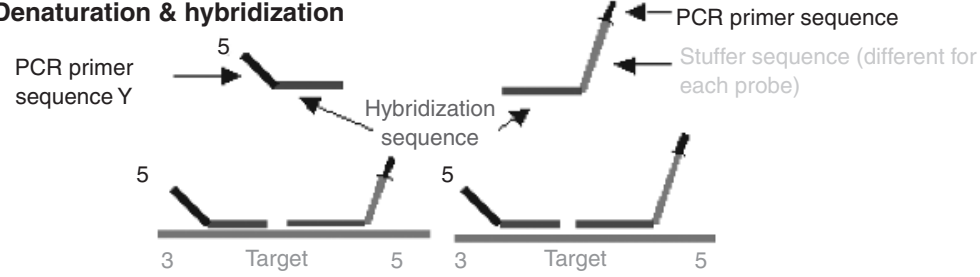

2. Ligation

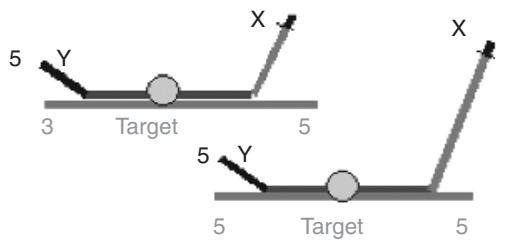

The two parts of each probe hybridize to adjacent target sequences and are ligated by a thermostable ligase.

3. PCR

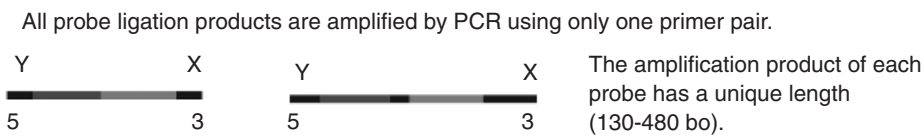

\section{Separation of amplification products by electrophoresis}

Amplification products are separated by electrophoresis. Relative amounts of probe amplification products, as compared to a control DNA sample, reflect the relative copy number of target sequences.

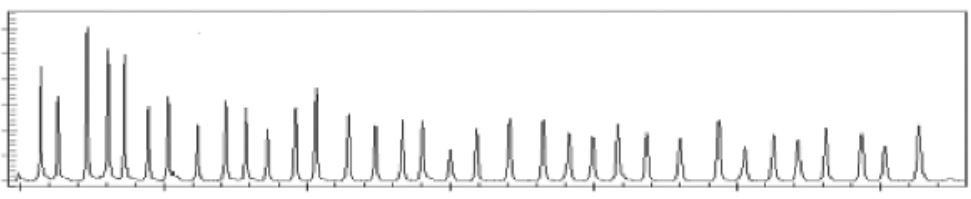

Detection of trisomies SALSA MLPA P001 Trisomy kit

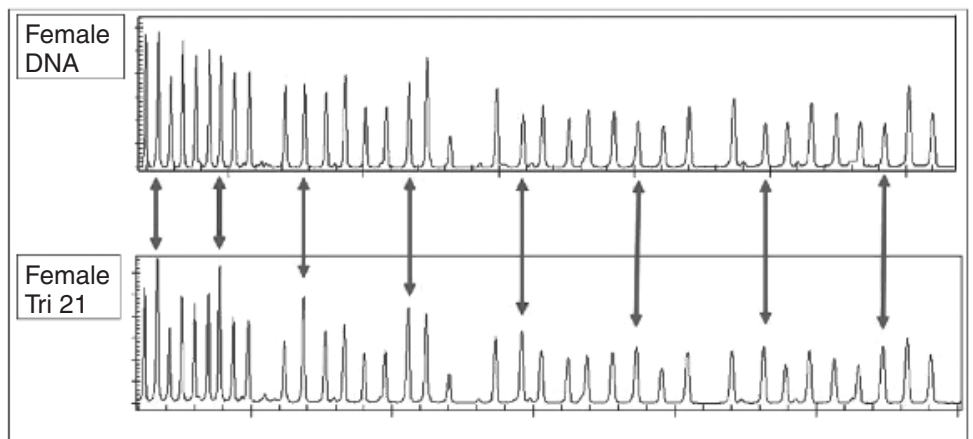

Chromosome 21 specific probes

Figure 1.3 Schematic of MLPA. The MLPA reaction is performed using four steps. Genomic DNA is denatured, whereafter the MLPA probes are added and incubated for $16 \mathrm{~h}$, allowing complete hybridization adjacent to all target sequences. Probes completely hybridized to sequences either side of each target region are subsequently ligated to each other, enabling their exponential PCR amplification and final detection, and quantification by capillary electrophoresis. (See Plate 1.3.) 


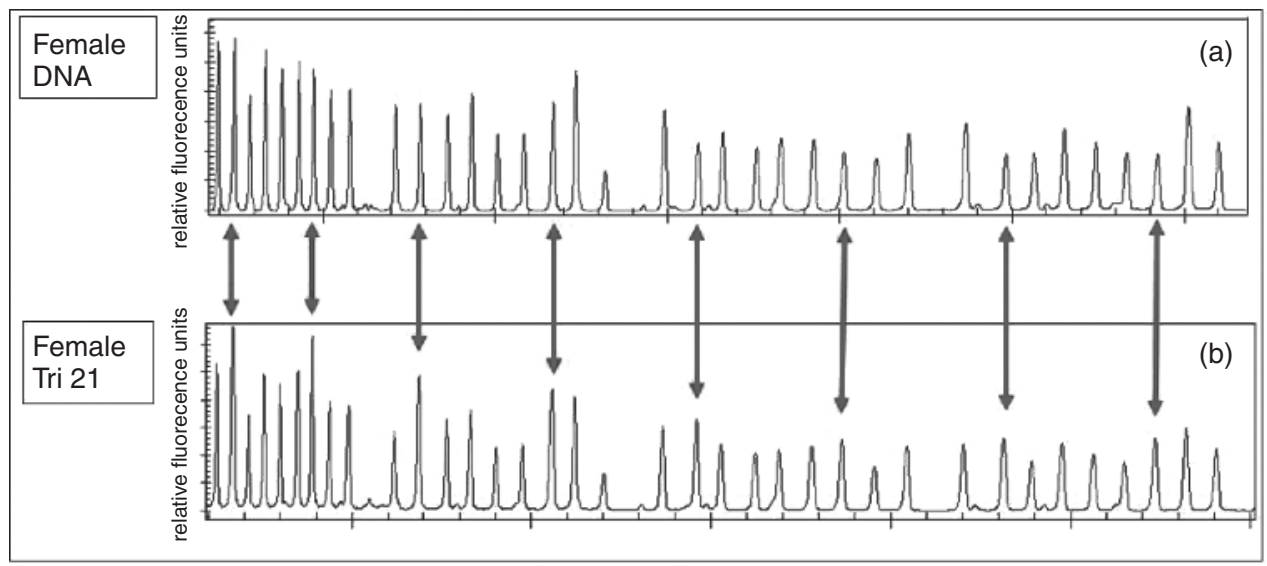

Figure 1.4 Detection of Down syndrome using the MLPA trisomy kit, including eight probes for sequences on each of chromosomes 13, 18, 21 and $X$, respectively, in addition to three probes for a chromosome $Y$ target sequence. The arrows indicate the chromosome 21 probes. (a) The electropherogram of an MLPA performed on normal female DNA. (b) MLPA performed on DNA from a Down syndrome patient, clearly showing an increase of all chromosome 21 probes.

such as: Down's syndrome (see Figure 1.4), breast (BRCA1) [37] and colon cancer [32] (MSH2 and MLH1), Duchenne [36], cystic fibrosis, centrifugal muscular atrophy, sickle cell anemia and Marfan syndrome, to name but a few. However, future MLPA kits will focus more on the detection of aberrations of genes playing roles in tumorigenesis, apoptosis, angiogenesis and pharmacogenetics.

\section{PROTOCOL 1.9 Multiplex Ligation-Dependent Probe Amplification on DNA}

\section{Equipment and reagents}

- Complete MLPA kit (MRC-Holland) containing:

- MLPA probe mix

- MLPA buffer

- Ligase-65 buffer $A$

- Ligase- 65 buffer $B$

- Ligase-65

- ultra pure water

- 10x SALSA PCR buffer

- 10× SALSA PCR buffer

- SALSA PCR forward primer (FAM or D4-labeled): 5'-GGGTTCCCTAAGGGTTGGA-3'

—SALSA PCR reverse primer (unlabeled): 5'-GTGCCAGCAAGATCCAATCTAGA-3' 
— SALSA enzyme dilution buffer

- SALSA polymerase

- Thermocycler (equipped with a heated lid) ${ }^{i i}$ programmed to perform the complete MLPA program:

- Hybridization program

- $98^{\circ} \mathrm{C}, 5 \mathrm{~min}$

- $25^{\circ} \mathrm{C}$, hold

- $95^{\circ} \mathrm{C}, 1 \mathrm{~min}$

- $60^{\circ} \mathrm{C}$, hold.

— Ligation program

- $54^{\circ} \mathrm{C}$, hold

- $54^{\circ} \mathrm{C}, 15 \mathrm{~min}$

- $98^{\circ} \mathrm{C}, 5 \mathrm{~min}$

- $4{ }^{\circ} \mathrm{C}$, hold.

- PCR program

- $60^{\circ} \mathrm{C}$, hold

- $\left(95^{\circ} \mathrm{C}, 30 \mathrm{~s} ; 60^{\circ} \mathrm{C}, 30 \mathrm{~s} ; 72{ }^{\circ} \mathrm{C}, 1 \mathrm{~min}\right) \times 35$

- $72^{\circ} \mathrm{C}, 20 \mathrm{~min}$

- $4{ }^{\circ} \mathrm{C}$, hold.

\section{Method}

1 In a pre-PCR location, measure the concentrations of the stock DNA solutions (see Protocol 1.3).

2 Dilute ${ }^{i j, k k}$ the DNA samples to working stocks of $10-20 \mathrm{ng} / \mu \mathrm{l}$ using $10 \mathrm{mM}$ Tris- $\mathrm{HCl}, \mathrm{pH}$ 8.0, 1 mM EDTA.

3 Label $0.2 \mathrm{ml}$ strip tubes with sample initials and probe set number.

4 Add $5 \mu$ l of a working stock DNA solution to each tube (or water for a water blank).

5 Centrifuge the strip tubes briefly to collect the sample DNA at the bottom.

6 Put the tubes into the thermocycler and start the MLPA program $\left(5\right.$ min at $\left.98^{\circ} \mathrm{C}\right)$; allow the samples to $\mathrm{cool}$ to $25^{\circ} \mathrm{C}$ before opening the thermocycler.

7 Remove the probe mix and the MLPA buffer from the $-20^{\circ} \mathrm{C}$ freezer and allow to thaw. Vortex briefly.

8 Prepare a probe master mix by combining (per DNA sample) $1.5 \mu \mathrm{l}$ of probe mix and $1.5 \mu$ l of MLPA buffer.

9 When the thermocycler reaches $25^{\circ} \mathrm{C}$, add $3 \mu \mathrm{l}$ of probe master mix to each DNA sample. Mix well by pipetting up and down. 
10 Continue the program on the thermocycler to advance from the $25^{\circ} \mathrm{C}$ hold step, incubating for $1 \mathrm{~min}$ at $95^{\circ} \mathrm{C}$, and then for $16 \mathrm{~h}$ (overnight) at $60^{\circ} \mathrm{C}$.

11 In a pre-PCR location, remove the Ligase- 65 buffer A and Ligase- 65 buffer B from the freezer and allow to thaw. Vortex briefly.

12 Prepare ${ }^{l l, m m, n n, 00}$ a ligase buffer mix by combining (for each reaction): $3 \mu$ l of Ligase-65 buffer $A, 3 \mu \mathrm{l}$ of Ligase- 65 buffer $B$ and $25 \mu \mathrm{l}$ of water. Mix by vortexing.

13 Add $1 \mu$ l of Ligase-65 (per reaction) to the ligase buffer mix and mix well by vortexing.

14 Continue the program on the thermocycler to advance to the $54^{\circ} \mathrm{C}$ hold step.

15 When the samples are at $54^{\circ} \mathrm{C}$, add $32 \mu \mathrm{l}$ of the ligase buffer plus Ligase- 65 mix to each reaction tube and mix well by pipetting up and down.

16 Continue the program on the thermocycler to advance to the next step (15 $\mathrm{min}$ incubation at $54^{\circ} \mathrm{C}$, followed by $5 \mathrm{~min}$ at $98^{\circ} \mathrm{C}$, and holding at $4^{\circ} \mathrm{C}$ ). Store ${ }^{p p}$ the ligation products at $4^{\circ} \mathrm{C}$ for up to 1 week.

17 In a pre-PCR location, remove $10 \times$ SALSA PCR buffer, SALSA PCR-primers and SALSA enzyme dilution buffer from the freezer and allow to thaw. Vortex briefly.

18 Label new tubes for PCR with the same sample initials and probe set numbers used for the hybridization and ligation reactions.

19 Prepare ${ }^{l l, m m, n n, 00}$ a PCR buffer mix by combining (per ligation product): $4 \mu \mathrm{l}$ of SALSA PCR buffer and $26 \mu \mathrm{l}$ of water. Mix by vortexing.

20 Add $30 \mu$ l of the PCR buffer mix to each new tube.

21 Transfer $10 \mu$ l of each ligation product to its corresponding PCR tube.

22 Centrifuge the strip tubes briefly in order to collect the reaction mixtures at the bottom of each tube.

23 Place tubes into the thermocycler.

24 On ice, prepare a PCR master mix combining (per ligation product): $2 \mu \mathrm{L}$ of SALSA primers, $2 \mu \mathrm{l}$ of SALSA enzyme dilution buffer and $5.5 \mu \mathrm{l}$ of water. Mix well by pipetting up and down.

25 Add $0.5 \mu$ l of SALSA polymerase to each reaction and carefully mix again by pipetting up and down.

26 Continue the program on the thermocycler to advance to the $60^{\circ} \mathrm{C}$ hold step.

27 Add $10 \mu \mathrm{l}$ of PCR mix to each PCR tube sitting in the thermocycler at $60^{\circ} \mathrm{C}$. Mix by pipetting up and down.

28 Continue the program, proceeding to exponential amplification..$^{q q}$

\section{Notes}

ii If no heated lid is available in the PCR machine, overlay each DNA sample with $15 \mu \mathrm{l}$ of mineral oil in order to prevent evaporation. 
ijIf the stock DNA solution concentrations are less than $10 \mathrm{ng} / \mu \mathrm{l}$, use the available concentration, but note that results may be less reliable. $50-100 \mathrm{ng}$ of DNA is recommended for each assay, although the acceptable range is $20-500 \mathrm{ng}$ of DNA.

${ }^{k}$ Both positive and negative controls (e.g. normal DNA and water respectively) can be processed in parallel.

"All MLPA reaction mixtures should be prepared less than $1 \mathrm{~h}$ before use and stored on ice.

${ }^{m m}$ All reagents should be returned to the freezer after usage, reducing the loss of activity of the enzymatic solutions.

${ }^{n n}$ Make master mix solutions for all reactions in an experiment in order to minimize sample to sample variation. Add $10 \%$ more than required of each reagent to account for pipetting loss.

${ }^{\circ}$ When performing MLPA on large sample numbers, multichannel pipettes are recommended.

${ }^{p p}$ For longer periods, storage at $-20^{\circ} \mathrm{C}$ is recommended.

${ }^{q q} \mathrm{PCR}$ products can be stored at $4^{\circ} \mathrm{C}$ for at least 1 week. As the fluorescent labels used are light sensitive, the PCR products should be stored in a dark box, or wrapped in aluminum foil.

\section{PROTOCOL 1.10 Separation and Relative Quantification of MLPA Products}

\section{Equipment and reagents}

- Capillary sequencer, or slab gel DNA sequencer, with fragment analysis software; for example

- ABI-310 (1 capillary) - capillary: 5-47 cm, $50 \mu \mathrm{m}$ (ABI 402839); polymer: POP-4 (ABI 4316355) or POP-6 (ABI 4306733)

-ABI-3100 (16 capillaries), or ABI 3100 Avant (four capillaries) - capillaries: $36 \mathrm{~cm}$; polymer: POP-4 (ABI 4316355)

- ABI-3700 (96 capillaries) - capillaries: 3700 capillary array, $50 \mathrm{~cm}$ (ABI 4305787); polymer: POP-4, or POP-6

- Deionized formamide (ABI, 4311320)

- Labelled size standard (ROX-500 ABI GeneScan 401734; TAMRA-500 ABI GeneScan 401733).

\section{rr Method}

ss, tt ABI-310:

1 Following the PCR reactions, for each reaction mix:

- $0.75 \mu \mathrm{l}$ of the PCR reaction

- $0.75 \mu \mathrm{l}$ of water 
- $0.5 \mu \mathrm{l}$ of ROX-labeled internal size standard

- $12 \mu \mathrm{l}$ of deionized formamide.

2 Mix by pipetting, incubate at $94^{\circ} \mathrm{C}$ for $2 \mathrm{~min}$ and cool on ice.

3 Start the fragment separation software using the following settings:

- injection time: $5 \mathrm{~s}$

- run voltage: $15 \mathrm{kV}$

- run time: $30 \mathrm{~min}$

- run temperature: $60^{\circ} \mathrm{C}$

- run voltage: $15 \mathrm{kV}$

- filter: C.

\section{ABI-3100 and ABI 3100 Avant: $^{\text {ss, tt }}$}

1 Following the PCR reactions, for each reaction mix:

- $0.5 \mu \mathrm{l}$ of ROX-labeled internal size standard

- $8.5 \mu \mathrm{l}$ of deionized formamide

- $1-3 \mu \mathrm{l}$ of the PCR reaction.

2 Pipette this mixture into the injection plate.

3 Seal the injection plate with plate sealing film and incubate at $92{ }^{\circ} \mathrm{C}$ for $2 \mathrm{~min}$, and hold at $4^{\circ} \mathrm{C}$ for $5 \mathrm{~min}$.

4 Start the fragment separation software using the following settings:

- run temperature: $60^{\circ} \mathrm{C}$

- capillary fill volume: 184 steps

- pre-run voltage: $15 \mathrm{kV}$

- pre-run time: $180 \mathrm{~s}$

- injection voltage: $3.0 \mathrm{kV}$

- injection time: $10-30 \mathrm{~s}$

- run voltage: $15 \mathrm{kV}$

- data delay time: $1 \mathrm{~s}$

- run time: $1500 \mathrm{~s}$.

\section{ABI-3700:ss, tt}

1 Following the PCR reactions, for each reaction mix:

- $2 \mu \mathrm{l}$ of the PCR reaction

- $0.2 \mu \mathrm{l}$ of ROX-labeled internal size standard

- $10 \mu \mathrm{l}$ of deionized formamide. 
2 Pipette this mixture into the injection plate.

3 Seal the injection plate with plate sealing film and incubate at $92^{\circ} \mathrm{C}$ for 2 min and hold at $4^{\circ} \mathrm{C}$ for $5 \mathrm{~min}$.

4 Start the fragment separation software using the following settings:

- sample volume: $2.5 \mu \mathrm{l}$

- injection time: $10 \mathrm{~s}$

- injection voltage: $10 \mathrm{kV}$

- run voltage: $7.5 \mathrm{kV}$

- run time: $4500 \mathrm{~s}$

- cuvette temperature: $48^{\circ} \mathrm{C}$

- run temperature: $50^{\circ} \mathrm{C}$

- filter set: D

\section{Notes}

${ }^{r r} \mathrm{~A}$ description of the methods and settings for a number of commercially available capillary sequencers is provided.

${ }^{\text {ss }}$ The amount of the MLPA PCR required for analysis by capillary electrophoresis depends on the apparatus and fluorescent label used.

${ }^{t t}$ Label for MLPA: SALSA 6-FAM PCR primer-dNTP mix.

\section{PROTOCOL 1.11 Normalization of MLPA Fragment Separations Results into Copy Number Ratios}

\section{Equipment and reagents}

- Capillary sequencer, or slab gel DNA sequencer, with fragment analysis software

- The MLPA probe mix list containing the genomic map coordinates of the probes

- The size-called fragment list(s) containing the size-called fragment lengths, heights and areas of samples, and their references ${ }^{u и}$

- Software which calculates ratios, links the genomic position of the probes and creates charts and reports for interpretation (e.g. Microsoft Excel, or dedicated software such as MLPA-DAT, Genemarker or Seq Pilot)

\section{Method $^{v v}$}

1 Load the probe list of your specific MLPA mix into the program.

2 Import your fragment list and define your reference data. ${ }^{\text {wW }}$ 
3 Examine the electropherogram patterns visually. ${ }^{x x}$

4 Separate probe signals from background signals by automatic binning and data filtering.

5 Quantify and normalize the probe signals (peaks). ${ }^{y y}$

6 Chart DNA copy number alterations according to genomic locations. ${ }^{2 z, a a a}$

\section{Notes}

${ }^{u и}$ MLPA product fragment lists should have the following plot settings - Genescan (ABI): dye, time, peak length, peak height, peak area; Genemapper (ABI): peak dye, sample file name, peak height, peak area.

${ }^{v}$ The protocol describes the creation of copy number ratio from MLPA product fragment lists using MLPA-DAT.

${ }^{w w}$ Reference runs are usually MLPA runs performed on normal human DNA samples within the same experiment as the samples. Multiple reference runs are recommended for probability calculation of the sample ratios found. Mean or median normalization are only recommended with larger sample numbers investigating syndromes with a low prevalence.

${ }^{x x}$ The DNA concentration, DNA ligation check and signal count are performed automatically.

${ }^{y y}$ Quantification is fully automated in MLPA-DAT and includes removal of individual run variance. The principle of normalization is twofold. First, all peak areas are converted into relative peak areas by dividing each by the sum of all peak areas. Second, a normalization factor is calculated from the ratio between the relative peak areas of all control probes of a sample and a reference DNA. Normalization settings may depend on the MLPA kit and type of sample analysed; for samples showing few aberrations, normalization can be done using all probes, but for samples with multiple chromosomal aberrations, such as tumor samples, it is recommended to use the control probes only. Control probe normalization sets the internal run normalization factor on a number of MLPA-probes known to remain constant in the expected sample types, while the amount of run variance is either determined on these probes only, or on all probes.

zzThis is automatic in MLPA-DAT.

${ }^{a a a} \mathrm{~A}$ deletion of one copy of a probe target sequence will usually be apparent by a reduction in relative peak area for that probe amplification product of $35-55 \%$. A gain in copy number from two to three copies/diploid genome will usually be apparent by an increase in relative peak area between 30 and $55 \%$.

\subsection{Troubleshooting}

- Low concentration of DNA isolated from FFPE tissue: When a low yield of DNA is expected from FFPE tissue, glycogen can be added as a co-precipitant prior to ethanol precipitation. This has no noticeable effect on aCGH results.

- DNA contaminants in MLPA: MLPA reactions are more sensitive to contaminants than ordinary PCR reactions. DNA samples extracted from FFPE tissues often contain contaminants. Small remnants of phenol may act as PCR inhibitors, giving amplification products with lower average peak areas. Reducing the amount of DNA used will therefore sometimes have a beneficial effect. Normalization of these DNA samples should be performed against DNA extracted from reference DNA of the same source of tissue. 
- Low MLPA peak areas: The quantity of a probe amplification product is primarily determined by the target sequence of the probe. MLPA probes located in guanine- and cytosine-rich areas often have difficulty reaching their target due to incomplete denaturation of the DNA. Better results may be obtained with these MLPA mixes by increasing the length of the initial denaturation step to $98^{\circ} \mathrm{C}$ for $10 \mathrm{~min}$. The probe signals are further influenced by the quality of the probe oligonucleotides and the amount of $\mathrm{KCl}$ and polymerase present during the PCR reaction. The polymerase activity may influence the relative signal strength of some probes; therefore, mixing the master mix well by pipetting up and down is strongly advised. It is also possible that the DNA input was too low. This is likely if the average signal of the four DQ (DNA quality) fragments is less than one-third of the ligation-dependent peak signal.

\section{References}

1. Kallioniemi, A., Kallioniemi, O.P., Sudar, D. et al. (1992) Comparative genomic hybridization for molecular cytogenetic analysis of solid tumors. Science, 258, 818-821. The original publication describing $\mathrm{CGH}$.

2. Kallioniemi, O.P., Kallioniemi, A., Piper, J. et al. (1994) Optimizing comparative genomic hybridization for analysis of DNA sequence copy number changes in solid tumors. Genes Chromosomes Cancer, 10, 231-243.

3. Oostlander, A.E., Meijer, G.A. and Ylstra, B. (2004) Microarray-based comparative genomic hybridization and its applications in human genetics. Clinical Genetics, 66, 488-495.

4. Solinas-Toldo, S., Lampel, S., Stilgenbauer, S. et al. (1997) Matrix-based comparative genomic hybridization: biochips to screen for genomic imbalances. Genes Chromosomes Cancer, 20, 399-407.

5. Pinkel, D., Segraves, R., Sudar, D. et al. (1998) High resolution analysis of DNA copy number variation using comparative genomic hybridization to microarrays. Nature Genetics, 20, 207-211. The original publication describing microarray CGH.

6. Ylstra, B., van den IJssel, P., Carvalho, B. et al. (2006) BAC to the future! or oligonucleotides: a perspective for micro array comparative genomic hybridization (array CGH). Nucleic Acids Res., 34, 445-450. Review of microarray CGH platforms.

7. Schouten, J.P., McElgunn, C.J., Waaijer, R. et al. (2002) Relative quantification of 40 nucleic acid sequences by multiplex ligation-dependent probe amplification. Nucleic Acids Res., 30, e57. The original publication describing MLPA.

8. Snijders, A.M., Nowak, N., Segraves, R. et al. (2001) Assembly of microarrays for genome-wide measurement of DNA copy number. Nature Genetics, 29, 263-264.

9. Ishkanian, A.S., Malloff, C.A., Watson, S.K. et al. (2004) Nature Genetics, 36, 299-303.

10. Pollack, J.R., Perou, C.M., Alizadeh, A.A. et al. (1999) Genome-wide analysis of DNA copy-number changes using cDNA microarrays. Nature Genetics, 23, 41-46.

11. Coe, B.P., Ylstra, B., Carvalho, B. et al. (2007) Resolving the resolution of array CGH. Genomics, 89, 647-653. Interesting paper on algorithms dealing with the resolution of diverse microarray CGH platforms.

12. Serth, J., Kuczyk, M.A., Paeslack, U. et al. (2000) Quantitation of DNA extracted after micropreparation of cells from frozen and formalin-fixed tissue sections. American Journal of Pathology, 156, 1189-1196. 
13. Nannya, Y., Sanada, M., Nakazaki, K. et al. (2005) A robust algorithm for copy number detection using high-density oligonucleotide single nucleotide polymorphism genotyping arrays. Cancer Research, 65, 6071-6079.

14. Van de Wiel, M.A., Kim, K.I., Vosse, S.J. et al. (2007) CGHcall: calling aberrations for array CGH tumor profiles. Bioinformatics, 23, 892-894.

15. Bignell, G.R., Huang, J., Greshock, J. et al. (2004) High-resolution analysis of DNA copy number using oligonucleotide microarrays. Genome Research, 14, 287-295.

16. Lindblad-Toh, K., Tanenbaum, D.M., Daly, M.J. et al. (2000) Loss-of-heterozygosity analysis of small-cell lung carcinomas using single-nucleotide polymorphism arrays. Nature Biotechnology, 18, 1001-1005.

17. Janne, P.A., Li, C., Zhao, X. et al. (2004) High-resolution single-nucleotide polymorphism array and clustering analysis of loss of heterozygosity in human lung cancer cell lines. Oncogene, 23, $2716-27262$.

18. Zhao, X., Li, C., Paez, J.G. et al. (2004) An integrated view of copy number and allelic alterations in the cancer genome using single nucleotide polymorphism arrays. Cancer Research, 64, 3060-3071.

19. Lips, E.H., Dierssen, J.W.F., van Eijk, R.R et al. (2005) Reliable high-throughput genotyping and loss-of-heterozygosity detection in formalin-fixed, paraffin-embedded tumors using single nucleotide polymorphism arrays. Cancer Research, 65, 10188-10191.

20. Kennedy, G.C., Matsuzaki, H., Dong, S. et al. (2003) Large-scale genotyping of complex DNA. Nature Biotechnology, 21, 1233-1237.

21. Matsuzaki, H., Loi, H., Dong, S. et al. (2004) Parallel genotyping of over 10,000 SNPs using a one-primer assay on a high-density oligonucleotide array. Genome Research, 14, 414-425.

22. Gunderson, K.L., Steemers, F.J., Lee, G. et al. (2005) A genome-wide scalable SNP genotyping assay using microarray technology. Nature Genetics, 37, 549-554.

23. Shen, R., Fan, J.B., Campbell, D. et al. (2005) High-throughput SNP genotyping on universal bead arrays. Mutation Research, 573, 70-82.

24. Hardenbol, P., Yu, F., Belmont, J. et al. (2005) Highly multiplexed molecular inversion probe genotyping: over 10,000 targeted SNPs genotyped in a single tube assay. Genome Research, 15, 269-275.

25. Oosting, J., Lips, E.H., van Eijk, R.R et al. (2007) High-resolution copy number analysis of paraffin-embedded archival tissue using SNP BeadArrays. Genome Research, 17, 368-376.

26. Ji, H., Kumm, J., Zhang, M. et al. (2006) Molecular inversion probe analysis of gene copy alterations reveals distinct categories of colorectal carcinoma. Cancer Research, 66, 7910-7919.

27. Lieberfarb, M.E., Lin, M., Lechpammer, M. et al. (2003) Genome-wide loss of heterozygosity analysis from laser capture microdissected prostate cancer using single nucleotide polymorphic allele (SNP) arrays and a novel bioinformatics platform dChipSNP. Cancer Research, 63, $4781-4785$.

28. Lin, M., Wei, L.J., Sellers, W.R. et al. (2004) dChipSNP: significance curve and clustering of SNP-array-based loss-of-heterozygosity data. Bioinformatics, 20, 1233-1240.

29. Ishikawa, S., Komura, D., Tsuji, S. et al. (2005) Allelic dosage analysis with genotyping microarrays. Biochemical and Biophysical Research Communications, 333, 1309-1314. 
30. Herr, A., Grutzmann, R., Matthaei, A. et al. (2005) High-resolution analysis of chromosomal imbalances using the Affymetrix 10K SNP genotyping chip. Genomics, 85, 392-400.

31. Eilers, P.H. and de Menezes, R.X. (2005) Quantile smoothing of array CGH data. Bioinformatics, 21, 1146-1153.

32. Gille, J.J.P., Hogervorst, F.B.L., Pals, G. et al. (2002) British Journal of Cancer, 87, 892-897.

33. Procter, M., Chou, L.S., Tang, W. et al. (2006) Molecular diagnosis of Prader-Willi and Angelman syndromes by methylation-specific melting analysis and methylation-specific multiplex ligation-dependent probe amplification. Clinical Chemistry, 52 (7), 1276-1283.

34. Hess, C.J., Denkers, F., Ossenkoppele, F.J. et al. (2004) Gene expression profiling of minimal residual disease in acute myeloid leukaemia by novel multiplex-PCR-based method. Leukemia, 18, 1981-1988.

35. Diego-Alvarez, D., Ramos-Corrales, C., Garcia-Hoyas, M. et al. (2006) Double trisomy in spontaneous miscarriages: cytogenetic and molecular approach. Human Reproduction, 21, 958-966.

36. Lalic, T.T, Vossen, R.H.A.M., Coffa, J. et al. (2005) Deletion and duplication screening in the DMD gene using MLPA. European Journal of Human Genetics, 13, 1231-1234.

37. Hogervorst, F.B.L., Nederlof, P.M., Gille, J.J.P. et al. (2003) Large genomic deletions and duplications in the BRCAl gene identified by a novel quantitative method. Cancer Research, 63, $1449-1453$.

38. Van Beers, E.H., Joosse, S.A., Ligtenberg, M.J. et al. (2006) A multiplex PCR predictor for aCGH success of FFPE samples. British Journal of Cancer, 94, 333-337. Describing a method for testing DNA quality of FFPE samples. 
